\title{
Prognostic value of sustained elevated C-reactive protein levels in patients with acute aortic intramural hematoma
}

\author{
Takeshi Kitai, MD, Shuichiro Kaji, MD, Kitae Kim, MD, Natsuhiko Ehara, MD, Tomoko Tani, MD, \\ Makoto Kinoshita, MD, and Yutaka Furukawa, MD
}

\begin{abstract}
Objectives: The appropriate management of aortic intramural hematoma is still controversial, because a variety of aortic events can arise during follow-up in some patients. However, simplified identification of these patients remains challenging. The present study aimed to determine the prognostic significance of serial C-reactive protein measurements for the prediction of adverse events in patients with acute aortic intramural hematoma.
\end{abstract}

\begin{abstract}
Methods: A total of 180 patients with aortic intramural hematoma were retrospectively reviewed. The C-reactive protein data were obtained at admission and 2 days, 1 week, and 2 weeks from the onset, and the maximum value was obtained during the acute phase. Adverse aorta-related events were defined by a composite of aortic rupture, aortic aneurysm, and surgical or endovascular aortic repair.
\end{abstract}

Results: The C-reactive protein value was $3.0 \pm 4.6,8.7 \pm 5.9,9.0 \pm 5.5$, and $5.7 \pm 4.5 \mathrm{mg} / \mathrm{dL}$ on admission and 2 days, 1 week, and 2 weeks from the onset, respectively. The maximal value of C-reactive protein was $12.4 \pm 6.3 \mathrm{mg} / \mathrm{dL}$ at a mean of 4 days from the onset. Patients with elevated C-reactive protein levels $(\geq 7.2$ $\mathrm{mg} / \mathrm{dL})$ at 2 weeks had significantly greater rates of aorta-related events $(P<.001)$. On multivariate analysis, an elevated $\mathrm{C}$-reactive protein level at 2 weeks (hazard ratio, 3.16; $P<.001$ ) and the development of an ulcer-like projection (hazard ratio, $2.68 ; P=.002$ ) were independent predictors of adverse aorta-related events. In addition, an elevated C-reactive protein level at 2 weeks had incremental value compared with the development of an ulcer-like projection (chi-square, 16.94 for ulcer-like projection only vs 34.32 with the addition of C-reactive protein at 2 weeks, $P<.001)$.

Conclusions: C-reactive protein was a simple and useful marker providing incremental prognostic information compared with the development of an ulcer-like projection in patients with aortic intramural hematoma. (J Thorac Cardiovasc Surg 2014;147:326-31)

Aortic intramural hematoma (IMH) has been recognized as a unique disease with pathologic and clinical features that differ from those of classic aortic dissection (AD) ${ }^{1,2} \mathrm{IMH}$ is often successfully managed by medical therapy, with lower mortality and morbidity rates than with classic $\mathrm{AD}^{3-6}$ However, a variety of aortic events can arise during follow-up in some patients. Although several imaging features, such as an ulcer-like projection (ULP), have been reported to be used to identify these high-risk patients, ${ }^{4,-10}$ simplified identification of these patients remains challenging.

Acute aortic syndrome is associated with a systemic activation of inflammation, reflected by a significant elevation

From the Department of Cardiovascular Medicine, Kobe City Medical Center General Hospital, Kobe, Japan.

This work was funded by the Department of Cardiovascular Medicine, Kobe City Medical Center General Hospital, Kobe, Japan.

Disclosures: Authors have nothing to disclose with regard to commercial support.

Received for publication July 24, 2012; revisions received Oct 8, 2012; accepted for publication Nov 9, 2012; available ahead of print Dec 10, 2012.

Address for reprints: Shuichiro Kaji, MD, Department of Cardiovascular Medicine,

Kobe City Medical Center General Hospital, 2-1-1 Minatojima-minamimachi,

Chuo-ku, Kobe 650-0047 Japan (E-mail: skaji@theia.ocn.ne.jp).

$0022-5223 / \$ 36.00$

Copyright (c) 2014 by The American Association for Thoracic Surgery

http://dx.doi.org/10.1016/j.jtcvs.2012.11.030 in inflammatory markers, including C-reactive protein (CRP). ${ }^{11-15}$ These elevated serologic markers can be caused by the underlying disease or the acute aortic pathologic entity itself. Recently, elevated serum CRP levels were reported to be associated with an adverse outcome in patients with classic AD. ${ }^{14,15}$ However, few data are available for patients with IMH regarding the association between CRP levels and clinical outcomes.

The present study aimed to determine the prognostic significance of serial CRP measurements for predicting adverse clinical events in patients with IMH.

\section{METHODS \\ Patient Characteristics}

We retrospectively reviewed the data from 180 patients, who were diagnosed with IMH within 48 hours from the onset, from January 1994 to March 2011 and for whom serial data for CRP within 2 weeks after onset and follow-up clinical data were available. We excluded patients who underwent emergency or urgent surgical or endovascular repair during the acute phase. Therefore, for type A IMH, we only included those patients who had a stable course with medical therapy only. Patients with type A IMH were treated as previously reported. ${ }^{5}$ Emergent surgery was performed in the case of complications, such as cardiac tamponade. Otherwise, supportive medical therapy was given initially, with tight blood pressure control. Timed surgery was performed in the case of disease progression, such as the development of an ULP in the ascending aorta. The 


\section{Abbreviations and Acronyms \\ $\mathrm{AD}=$ aortic dissection \\ $\mathrm{CRP}=$ C-reactive protein \\ $\mathrm{CT}=$ computed tomography \\ $\mathrm{IMH}=$ intramural hematoma \\ MDCT $=$ multidetector CT \\ $\mathrm{ULP}=$ ulcer-like projection}

diagnoses were established by contrast-enhanced computed tomography (CT) and confirmed by transesophageal echocardiography when the diagnosis by CT was inconclusive. IMH was defined as a crescentic or circular high-attenuation area along the aortic wall without contrast enhancement on the CT scan and regional aortic wall thickening on the transesophageal echocardiogram without evidence of direct flow communication. The institutional review board approved the present study.

\section{CRP Measurement}

The CRP data were measured at admission and 2 days, 1 week (6-8 days), 2 weeks (13-15 days) from the onset of IMH, and the maximal value during the acute phase was recorded. These data were retrospectively obtained from the medical records. CRP was measured by latex agglutination nephelometry (IatroCRP-Ex, Mitsubishi Chemical Medience, Tokyo, Japan) using an autoanalyzer (Hitachi7600, Hitachi, Tokyo, Japan). Because we have routinely measured CRP levels during hospitalization in patients with acute IMH, no patients had unavailable CRP data during the acute phase.

\section{Clinical Follow-up and CT Evaluation}

The mean follow-up period was $5.1 \pm 3.9$ years. Adverse aorta-related events were defined by a composite of aortic rupture, aortic enlargement $(\geq 60 \mathrm{~mm}$ ), and surgical or endovascular aortic repair. The development of an ULP was assessed by comparing the initial and follow-up CT images. An ULP was defined as a localized blood-filled pouch protruding into the thrombosed false lumen, as previously described. ${ }^{7,8}$ All images and diagnoses were reassessed by 2 experienced readers (K.K. and S.K.) according to current knowledge.

\section{Statistical Analysis}

The categorical variables are reported as numbers and percentages and were compared using the chi-square test or Fisher's exact test, as appropriate. Continuous variables are reported as the mean \pm standard deviation and were compared using unpaired $t$ tests. Because of the skewed distribution of CRP and the white blood cell count, a nonparametric test (Mann-Whitney $U$ test) was used to compare the values between the groups. A nonparametric repeated-measures analysis of variance (Friedman test) was used to test statistical differences in the CRP values with time among the groups, and the Wilcoxon signed-rank test was used to test statistical differences between each time group. Survival analysis was performed using Kaplan-Meier analysis, and differences in survival between the groups were examined with the log-rank test. To determine the predictors for adverse aortarelated events during the follow-up period, the Cox proportional hazards model was used to estimate the risk of the following potential variables: age, gender, Stanford type, hypertension, diabetes mellitus, hyperlipidemia, ischemic heart disease, previous stroke, renal insufficiency (defined as estimated glomerular filtration rate $<60 \mathrm{~mL} / \mathrm{min} / 1.73 \mathrm{~m}^{2}$ ), chronic obstructive pulmonary disease, development of an ULP, and high CRP levels at 2 weeks from onset. Those variables for which the probability values were $<.20$ on univariate analyses and for which the proportionality assumptions were generally fair were included in the multivariate analysis. The multivariate Cox proportional hazard model was built by stepwise variable selection with entry and removal exit criteria set at $P=.05$ and $P=.10$, respectively. For additional comparison of the prognostic value of CRP and to determine the cutoff values, receiver operating characteristics curves were generated, and the area under the curves was calculated.

An incremental prognostic value was defined as a significant increase in the Wald statistic and likelihood ratio tests after the addition of CRP data to an optimized Cox model of ULP data alone. Incremental prognostic value was considered to be present for any of these steps when a significant increase in Wald global chi-square value was found. The C-statistics index was also calculated to assess the model discrimination, the ability of the model to correctly identify with respect to aorta-related events. The Harrell $\mathrm{C}$-index was the primary measure of discrimination. ${ }^{16}$ The increased discriminative value of the CRP level, in addition to the previously documented value of the development of ULP, was further examined using the method described by Pencina et al. ${ }^{17}$

All analyses were performed with SPSS software, version 17.0 (SPSS, Chicago, Ill), and R, version 2.3.1 system (R Foundation for Statistical Computing, Vienna, Austria).

\section{RESULTS \\ Overall Patient Characteristics and Clinical Outcomes}

Of the 180 patients, 101 were men and 79 were women, with a mean age of $70 \pm 11$ years. Of the 180 patients, 40 were diagnosed with Stanford type A IMH and 140 with type B IMH. All patients, including those with type A IMH, were treated medically, as previously reported. ${ }^{5,8}$ All study patients underwent follow-up CT, and the mean duration between admission and the follow-up CT scan was $30 \pm 42$ days. In addition, the duration between admission and the last follow-up CT scan was $3.6 \pm 3.8$ years. The mean number of CT scans per patient was 7.4. During follow-up, 49 patients had adverse aorta-related events. Of these patients, 8 died of aortic rupture (2 patients with an initial diagnosis of type A IMH and 6 with type B IMH), 23 underwent surgical or endovascular aortic repair ( 4 for repeat dissection of the ascending aorta, 16 for aortic aneurysm, defined as $\geq 60 \mathrm{~mm}$ for the thoracic aorta or $\geq 50 \mathrm{~mm}$ for the abdominal aorta, and 3 for impending rupture), and 18 had significant aortic dilatation without surgery (defined as $\geq 60 \mathrm{~mm}$ for the thoracic aorta or $\geq 50 \mathrm{~mm}$ for the abdominal aorta). The clinical features of the patients with aorta-related events and those without these events are listed in Table 1.

\section{Time Course Change in CRP Levels}

Figure 1, $A$ shows the time course change in CRP levels. The mean CRP level on admission and 2 days, 1 week, and 2 weeks from onset was $3.0 \pm 4.6,8.7 \pm 5.9,9.0 \pm 5.5$, and $5.7 \pm 4.5 \mathrm{mg} / \mathrm{dL}$, respectively. The maximum CRP value was $12.4 \pm 6.3 \mathrm{mg} / \mathrm{dL}$ at $4 \pm 2$ days from onset. The maximal diameter of the ascending aorta, maximal hematoma thickness, and peak CRP value of the 40 patients with type A IMH was $46.0 \pm 4.3 \mathrm{~mm}, 9.6 \pm 3.4 \mathrm{~mm}$, and $14.0 \pm 6.7 \mathrm{mg} / \mathrm{dL}$, respectively. No significant correlations were found between the peak CRP level and maximal diameter of the ascending aorta or maximal hematoma thickness in these stable patients. 
TABLE 1. Patient characteristics

\begin{tabular}{|c|c|c|c|}
\hline \multirow[b]{2}{*}{ Characteristic } & \multicolumn{2}{|c|}{ Aortic event } & \multirow[b]{2}{*}{$\begin{array}{c}P \\
\text { value } \\
\end{array}$} \\
\hline & $\begin{array}{c}\text { Yes } \\
(n=49)\end{array}$ & $\begin{array}{c}\text { No } \\
(n=131)\end{array}$ & \\
\hline Age (y) & $71 \pm 8$ & $69 \pm 11$ & .19 \\
\hline Men (n) & $27(55)$ & $74(57)$ & .87 \\
\hline Stanford type & & & .72 \\
\hline A & 10 & 30 & \\
\hline $\mathrm{B}$ & 39 & 101 & \\
\hline Hypertension (n) & $43(88)$ & $113(86)$ & .79 \\
\hline Diabetes mellitus (n) & $9(18)$ & $31(24)$ & .45 \\
\hline Hyperlipidemia (n) & $20(41)$ & $45(34)$ & .42 \\
\hline Smoking (n) & $20(41)$ & $43(33)$ & .32 \\
\hline Previous stroke (n) & $10(20)$ & $18(14)$ & .27 \\
\hline Ischemic heart disease (n) & $3(6)$ & $14(11)$ & .27 \\
\hline Renal insufficiency (n) & $27(55)$ & $78(60)$ & .59 \\
\hline $\operatorname{COPD}(n)$ & $1(2)$ & $1(1)$ & .47 \\
\hline \multicolumn{4}{|l|}{ Antihypertensive therapy (n) } \\
\hline Calcium antagonist & $44(90)$ & $115(88)$ & .71 \\
\hline$\beta$-Blocker & $45(92)$ & $112(86)$ & .26 \\
\hline ACEI/ARB & $23(47)$ & $66(50)$ & .68 \\
\hline \multicolumn{4}{|c|}{ Systolic BP at first follow-up visit } \\
\hline$\leq 120 \mathrm{~mm} \mathrm{Hg}$ & $20(41)$ & $54(41)$ & .96 \\
\hline $121-140 \mathrm{~mm} \mathrm{Hg}$ & $19(39)$ & $49(37)$ & .87 \\
\hline$>140 \mathrm{~mm} \mathrm{Hg}$ & $7(14)$ & $20(15)$ & .87 \\
\hline Development of ULP (n) & $35(71)$ & $32(24)$ & $<.001$ \\
\hline \multicolumn{4}{|l|}{ CRP level (mg/dL) } \\
\hline On admission & $4.7 \pm 5.6$ & $2.4 \pm 4.0$ & .008 \\
\hline 2 days from onset & $11.4 \pm 6.2$ & $7.9 \pm 5.6$ & .002 \\
\hline 1 week from onset & $11.3 \pm 5.7$ & $8.1 \pm 5.2$ & .001 \\
\hline 2 weeks from onset & $8.8 \pm 5.2$ & $4.5 \pm 3.6$ & $<.001$ \\
\hline Maximal value & $15.4 \pm 6.0$ & $11.3 \pm 6.1$ & $<.001$ \\
\hline \multicolumn{4}{|c|}{ WBC measurement $\left(\times 10^{3}\right.$ count $\left./ \mathrm{mm}^{3}\right)$} \\
\hline On admission & $10.2 \pm 3.6$ & $10.4 \pm 3.9$ & .76 \\
\hline 2 days from onset & $10.1 \pm 3.5$ & $9.7 \pm 3.4$ & .36 \\
\hline 1 week from onset & $8.6 \pm 3.0$ & $7.6 \pm 2.4$ & .04 \\
\hline 2 weeks from onset & $7.6 \pm 2.5$ & $7.2 \pm 2.4$ & .23 \\
\hline Maximal value & $11.8 \pm 3.7$ & $11.6 \pm 4.1$ & .70 \\
\hline
\end{tabular}

Because the surgical intervention itself is thought to have a great effect on the CRP levels, we excluded 25 patients (22 with type A IMH and 3 with type B IMH) who had undergone surgical intervention within 2 weeks from onset. The mean interval from symptom onset to intervention for those patients was 1.4 days, and the mean CRP value at intervention was $8.8 \pm 7.9 \mathrm{mg} / \mathrm{dL}$.

The patients with aorta-related events had significantly greater CRP levels than those without aorta-related events on admission and 2 days, 1 week, and 2 weeks from onset and greater maximal CRP levels (Table 1 and Figure 1,B).

\section{New ULP Development}

Of the 180 study patients, 67 showed newly developed ULP on the follow-up CT images. The mean interval to the diagnosis of ULP development from the onset of symptoms was 24 days (range, 6-90 days). At more than 3 months of follow-up, no patients showed new ULP development. Of the 40 patients with type A IMH, 12 showed an ULP at the aortic arch or descending aorta, and only 1 patient had an ULP at the ascending aorta. Patients with newly developed ULP had greater CRP levels at 2 weeks from onset $(7.5 \pm 5.0$ vs $4.6 \pm 3.8 \mathrm{mg} / \mathrm{dL}, P<.001)$ and greater peak CRP levels $(14.2 \pm 6.3$ vs $11.4 \pm 6.1 \mathrm{mg} / \mathrm{dL}$, $P=.007)$ than those without an ULP.

\section{Predictors of Adverse Aorta-Related Events}

Receiver operating characteristics curve analysis identified a CRP level of $7.2 \mathrm{mg} / \mathrm{dL}$ or more at 2 weeks from onset as a cutoff for predicting future aorta-related events (area under the curve, 0.76 ; $95 \%$ confidence interval, 0.68 $0.84 ; P<.001)$ with sensitivity, specificity, and positive and negative predictive value of $63 \%, 80 \%, 54 \%$, and $85 \%$, respectively. Patients with elevated CRP levels $(\geq 7.2 \mathrm{mg} / \mathrm{dL})$ at 2 weeks had significantly greater rates of aorta-related events than those with CRP levels less than $7.2 \mathrm{mg} / \mathrm{dL}(P<.001$, Figure $2, A)$. Similarly, peak CRP levels of $12.0 \mathrm{mg} / \mathrm{dL}$ or greater (area under the curve, $0.68 ; 95 \%$ confidence interval, $0.59-0.76 ; P<.001)$ was identified as a cutoff value, with a sensitivity, specificity, and positive and negative predictive value of $73 \%, 56 \%$, $43 \%$, and $85 \%$, respectively.

The results of the univariate and multivariate analyses for the predictors of adverse aorta-related events are listed in Table 2. A CRP level of $7.2 \mathrm{mg} / \mathrm{dL}$ or more at 2 weeks from the onset of IMH and the development of ULP were confirmed as the strongest independent predictors of aorta-related events. In addition, the incremental value of CRP over the development of ULP was determined using the following survival models: model 1, which incorporated ULP only; model 2, which incorporated ULP and the maximal CRP value; and model 3, which incorporated ULP and CRP at 2 weeks from the onset of IMH (Table 3). Model 3 revealed a significantly greater increased chi-square and $\mathrm{C}$-statistic, indicating that elevated CRP levels at 2 weeks had incremental value over the development of ULP (Table 3 ).

Figure 2, $B$ shows the aorta-related event-free survival among the 4 subgroups, classified by both CRP level at 2 weeks from the onset of IMH and the development of ULP. Concomitance of elevated CRP levels and ULP was associated with a poor prognosis among the groups.

\section{DISCUSSION}

The present study reports the clinical usefulness of serial CRP measurement for identifying high-risk patients with IMH. The main findings of the present study were as follows: elevated CRP levels $(\geq 7.2 \mathrm{mg} / \mathrm{dL})$ at 2 weeks from the onset of IMH were independently associated with adverse aorta-related events; and CRP measurement 

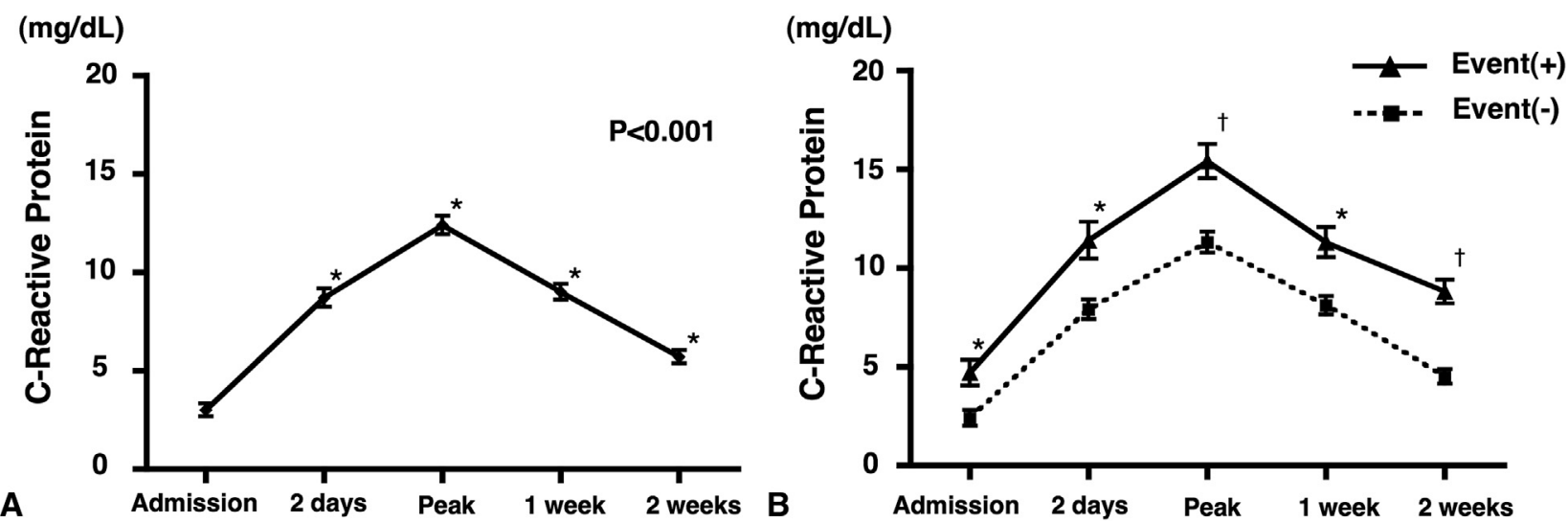

FIGURE 1. Kinetics of release of C-reactive protein $(C R P)$ levels in patients with intramural hematoma. A, Time course change in mean CRP levels in all study patients with acute aortic intramural hematoma. Error bars indicate standard error of the mean. $* P<.001$ compared with CRP level on admission. $\mathrm{B}$, Comparison of time course change in mean CRP levels and standard error of the mean in patients with intramural hematoma with and without adverse aorta-related events. Error bars indicate standard error of the mean. $* P<.01$ and $\dagger P<.001$ compared with patients without aorta-related events.

provided incremental prognostic information over the development of ULP.

CRP is an acute-phase reactant that reflects different degrees of inflammation and systemic stress and is a simple marker widely available for clinical use. CRP has been identified as an independent risk factor for a variety of cardiovascular diseases. ${ }^{18-21}$ Recently, an inflammatory mechanism has been shown to be involved in medial degeneration, with an association with clinical manifestations of acute aortic syndrome. ${ }^{11,13}$ Additionally, inflammatory processes play a pathophysiologic role in the development and progression of aortic disease. ${ }^{8}$ CRP is inevitably elevated in patients with acute aortic syndrome. Furthermore, it has been reported that elevated CRP levels are associated with adverse aortic events in patients with classic AD. ${ }^{14,15}$ The present study demonstrated that CRP levels peaked within 1 week and consistently elevated CRP levels during the acute phase were associated with poor clinical outcomes in patients with IMH. The possible explanation for why the elevated CRP levels had prognostic information in patients with IMH is that the CRP levels might represent the extent of inflammatory reaction in the involved aorta and reflect the damage to the lesion of the aortic wall. Several previous

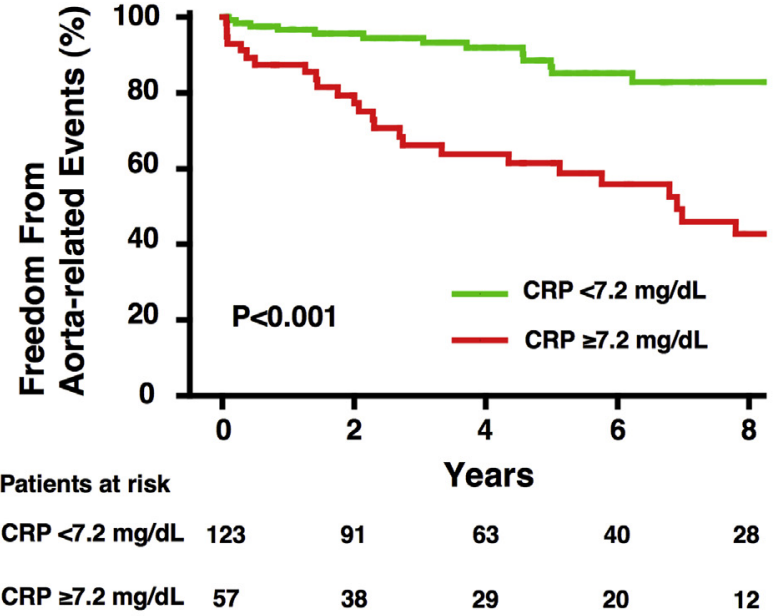

A

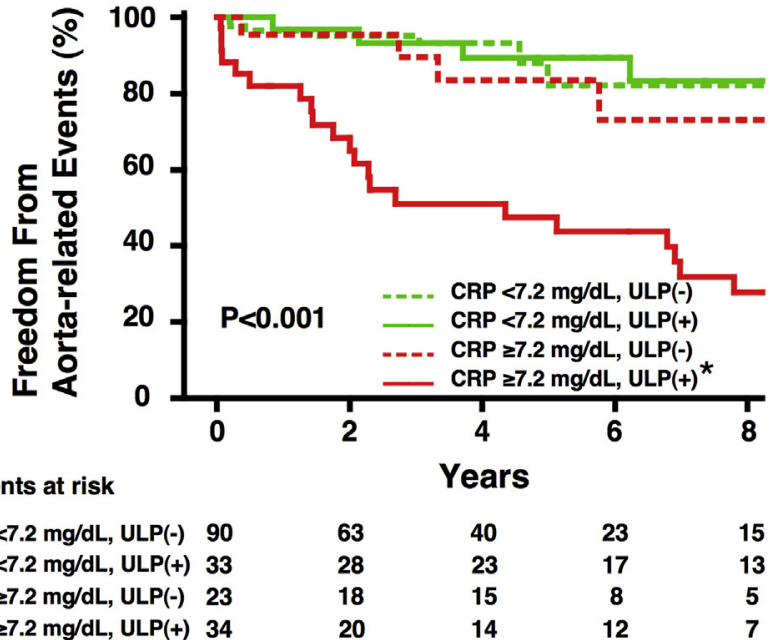

B

FIGURE 2. Interval to adverse aorta-related event in patients with intramural hematoma. Comparison of aorta-related event-free survival curve in patients with (A) C-reactive protein (CRP) of $7.2 \mathrm{mg} / \mathrm{dL}$ or more at 2 weeks from onset and those with CRP less than $7.2 \mathrm{mg} / \mathrm{dL}$ and (B) among 4 subgroups: CRP less than $7.2 \mathrm{mg} / \mathrm{dL}$ without ulcer-like projection $(U L P)$, CRP less than $7.2 \mathrm{mg} / \mathrm{dL}$ with ULP, CRP of $7.2 \mathrm{mg} / \mathrm{dL}$ or more without ULP, and CRP of $7.2 \mathrm{mg} / \mathrm{dL}$ or more with ULP. $* P<.001$ compared with CRP less than $7.2 \mathrm{mg} / \mathrm{dL}$ without ULP, CRP less than $7.2 \mathrm{mg} / \mathrm{dL}$ with ULP, and CRP of $7.2 \mathrm{mg} / \mathrm{dL}$ or more without ULP, respectively. Adverse aorta-related events included aortic rupture, aortic surgery, and significant aortic aneurysm without surgery. 
TABLE 2. Univariate and multivariate analysis of predictors of adverse aorta-related events

\begin{tabular}{|c|c|c|c|c|}
\hline \multirow[b]{2}{*}{ Variable } & \multicolumn{2}{|c|}{$\begin{array}{l}\text { Univariate } \\
\text { predictors }\end{array}$} & \multicolumn{2}{|c|}{$\begin{array}{c}\text { Multivariate } \\
\text { predictors }\end{array}$} \\
\hline & $\begin{array}{c}\text { HR } \\
(95 \% \mathrm{CI})\end{array}$ & $\begin{array}{c}P \\
\text { value* }\end{array}$ & $\begin{array}{c}\text { HR } \\
(95 \% \mathrm{CI})\end{array}$ & $\begin{array}{c}P \\
\text { value* }^{*}\end{array}$ \\
\hline Age $(>75$ y) & $1.47(0.82-2.63)$ & .19 & - & - \\
\hline Men & $0.71(0.41-1.26)$ & .24 & - & - \\
\hline Stanford type A & $0.73(0.36-1.46)$ & .37 & - & - \\
\hline Development of ULP & $3.45(1.84-6.44)$ & $<.001$ & $2.68(1.42-5.07)$ & .002 \\
\hline $\begin{array}{l}\mathrm{CRP} \geq 7.2 \mathrm{mg} / \mathrm{dL} \text { at } \\
\quad 2 \mathrm{wk}\end{array}$ & 3.89 (2.18-6.97) & $<.001$ & $3.16(1.74-5.73)$ & $<.001$ \\
\hline Hypertension & $0.93(0.39-2.19)$ & .87 & - & - \\
\hline Diabetes mellitus & $0.84(0.41-1.73)$ & .64 & - & - \\
\hline Hyperlipidemia & $1.46(0.82-2.58)$ & .20 & - & - \\
\hline Ischemic heart disease & $0.86(0.27-2.79)$ & .81 & - & - \\
\hline Previous stroke & $1.43(0.71-2.89)$ & .32 & - & - \\
\hline Renal insufficiency & $1.03(0.72-1.47)$ & .89 & - & - \\
\hline COPD & $1.66(0.09-7.56)$ & .64 & - & - \\
\hline
\end{tabular}

studies have suggested that inflammation exists in the involved aorta in patients with classic AD. ${ }^{11,13,14}$ Our findings suggest that inflammation of the involved aorta is present in those with IMH just as in those with classic AD and that a severely damaged aortic wall might be more prone to lead to adverse aorta-related events.

In the present study, the CRP levels in patients with aortarelated events increased to greater peak values and had sustained elevation at 2 weeks than in those without aortarelated events. These sustained greater CRP levels might be indicative of residual inflammation of the localized lesion, such as new intimal disruption, which leads to the development of ULP. ULP has been reported to be strong predictor of adverse aorta-related events in patients with IMH. ${ }^{4,7,8}$ In the present study, patients with the new development of an ULP also had greater CRP levels at 2 weeks from the onset of IMH than those without an ULP. Thus, elevated CRP levels might be partially associated with an ulcerative lesion of the involved aorta, another possible explanation of why CRP levels are associated with adverse events in patients with IMH. However, the results of the present study demonstrated that elevated CRP values could provide incremental prognostic information over the development of an ULP in patients with IMH. Therefore, only development of an ULP or ulcerative lesion in the involved aorta cannot explain the relationship between the elevated CRP levels and poor clinical outcomes.

In the present study, the peak CRP levels and CRP levels at 2 weeks after onset in patients with IMH had significant prognostic information. Sakakura and colleagues ${ }^{14}$ demonstrated that peak CRP values are associated with long-term outcomes in patients with classic AD. In our patients with IMH, although the peak CRP levels were also associated with adverse aorta-related events, the CRP levels at 2 weeks provided better prognostic value. This finding suggests that the healing process of aortic pathologic features might provide more important prognostic information than the severity of aortic inflammation in patients with IMH. Additional investigations are necessary to elucidate the precise mechanism of the association between elevated CRP levels and adverse clinical events.

\section{Study Limitations}

The present study had several limitations that should be acknowledged. First, we included patients with type A $\mathrm{IMH}$, who might be supposed to have different clinical courses than patients with type B IMH. However, we excluded those with type A IMH who underwent emergency surgery because of complications or timed surgery because of progression in the ascending aorta during the acute phase. Thus, the Stanford type did not significantly affect the outcome in the present study. Second, we diagnosed the disease using axial CT and, partly, transesophageal echocardiography, from both of which the presence of ULP could have been overlooked. $^{22}$ In addition, the timing of the followup CT scan might have affected the detection of ULP development. Earlier follow-up CT studies might have missed ULP development. Furthermore, the size of the ULP was not assessed in the present study. This was because a limited number of patients underwent multidetector CT (MDCT). A previous study reported that MDCT was recommended

TABLE 3. Incremental value of different measurement points of CRP over ULP

\begin{tabular}{|c|c|c|c|c|c|c|}
\hline Variable & HR $(95 \%$ CI $)$ & $P$ value* & Chi-square & $P$ value & C statistic $(95 \%$ CI $)$ & $P$ value \\
\hline Model 1 & & & 16.94 & Reference & $0.644(0.565-0.723)$ & Reference \\
\hline ULP & $3.45(1.84-6.44)$ & $<.001$ & & & & \\
\hline Model 2 & & & 24.68 & .004 & $0.700(0.622-0.778)$ & .040 \\
\hline ULP & $2.81(1.48-5.33)$ & .002 & & & & \\
\hline Peak CRP & $2.45(1.28-4.70)$ & .007 & & & & \\
\hline Model 3 & & & 34.32 & $<.001$ & $0.710(0.621-0.800)$ & $<.001$ \\
\hline ULP & $2.68(1.42-5.07)$ & .002 & & & & \\
\hline $\mathrm{CRP}$ at $2 \mathrm{wk}$ & $3.16(1.74-5.73)$ & $<.001$ & & & & \\
\hline
\end{tabular}

$H R$, Hazard ratio; $C I$, confidence interval; $U L P$, ulcer-like projection; $C R P$, C-reactive protein. *Cox proportional hazard model analysis. 
to obtain detailed information of the depth, length, and height of the small intimal defect in the entire aorta. ${ }^{22}$ It might be difficult to evaluate the precise ULP size without using MDCT. Additional studies with MDCT are required to investigate the relationship between the radiographic features of ULP and the prognosis of patients with IMH. Third, CRP is a nonspecific inflammatory marker; it reflects, not only the extent of the aortic dissection itself, but also concomitant inflammatory disease such as pneumonia. Finally, we did not include the aortic diameter and hematoma thickness as variables to predict aorta-related events. In the present study, most of the study patients had type B IMH, with a maximal diameter that varied depending on the portions of the affected aorta. Furthermore, we excluded patients with type A IMH who had undergone surgical intervention within 2 weeks of the onset of IMH. It would be difficult to regard measures of the different portions of the diseased aorta as the same predictive variable.

\section{Clinical Implications}

It has been reported that patients with newly developed ULP should be carefully followed up with frequent imaging studies, because the ULP frequently progresses. ${ }^{7,8}$ Risk stratification of IMH has been established using only imaging modalities. However, frequent CT can lead to excessive radiation and contrast exposure. From our data, the serum CRP level is a simpler and less-invasive marker for identifying high-risk patients, and it might reduce the necessity for follow-up CT examinations.

In addition, our results suggest that sustained high CRP levels might represent residual aortic inflammation, leading to future aorta-related events. Anti-inflammatory or anticytokine therapy might have a possible role in reducing future aorta-related events, especially in patients with elevated CRP levels. ${ }^{12}$

\section{References}

1. Evangelista A, Mukherjee D, Mehta RH, O'Gara PT, Fattori R, Cooper JV, et al. Acute intramural hematoma of the aorta: a mystery in evolution. Circulation. 2005;111:1063-70.

2. Nienaber CA, von Kodolitsch Y, Petersen B, Loose R, Helmchen U, Haverich A, et al. Intramural hemorrhage of the thoracic aorta: diagnostic and therapeutic implications. Circulation. 1995;92:1465-72.

3. Kaji S, Akasaka T, Horibata Y, Nishigami K, Shono H, Katayama M, et al. Longterm prognosis of patients with type a aortic intramural hematoma. Circulation. 2002;106(Suppl 1):I248-52.
4. Kaji S, Akasaka T, Katayama M, Yamamuro A, Yamabe K, Tamita K, et al. Long-term prognosis of patients with type B aortic intramural hematoma. Circulation. 2003;108(Suppl 1):II307-11.

5. Kitai T, Kaji S, Yamamuro A, Tani T, Tamita K, Kinoshita M, et al. Clinical outcomes of medical therapy and timely operation in initially diagnosed type A aortic intramural hematoma: a 20-year experience. Circulation. 2009;120:S292-8.

6. Song JK, Kim HS, Kang DH, Lim TH, Song MG, Park SW, et al. Different clinical features of aortic intramural hematoma versus dissection involving the ascending aorta. J Am Coll Cardiol. 2001;37:1604-10.

7. Sueyoshi E, Matsuoka Y, Imada T, Okimoto T, Sakamoto I, Hayashi K. New development of an ulcerlike projection in aortic intramural hematoma: CT evaluation. Radiology. 2002;224:536-41.

8. Kitai T, Kaji S, Yamamuro A, Tani T, Kinoshita M, Ehara N, et al. Impact of new development of ulcer-like projection on clinical outcomes in patients with type B aortic dissection with closed and thrombosed false lumen. Circulation. 2010; 122:S74-80

9. Tittle SL, Lynch RJ, Cole PE, Singh HS, Rizzo JA, Kopf GS, et al. Midterm follow-up of penetrating ulcer and intramural hematoma of the aorta. J Thorac Cardiovasc Surg. 2002;123:1051-9.

10. Moizumi Y, Komatsu T, Motoyoshi N, Tabayashi K. Clinical features and longterm outcome of type A and type B intramural hematoma of the aorta. $J$ Thorac Cardiovasc Surg. 2004;127:421-7.

11. He R, Guo DC, Estrera AL, Safi HJ, Huynh TT, Yin Z, et al. Characterization of the inflammatory and apoptotic cells in the aortas of patients with ascending thoracic aortic aneurysms and dissections. J Thorac Cardiovasc Surg. 2006;131: 671-8.

12. Komukai K, Shibata T, Mochizuki S. C-reactive protein is related to impaired oxygenation in patients with acute aortic dissection. Int Heart J. 2005;46:795-9.

13. Kuehl H, Eggebrecht H, Boes T, Antoch G, Rosenbaum S, Ladd S, et al. Detection of inflammation in patients with acute aortic syndrome: comparison of FDGPET/CT imaging and serological markers of inflammation. Heart. 2008;94 1472-7.

14. Sakakura K, Kubo N, Ako J, Wada H, Fujiwara N, Funayama H, et al. Peak C-reactive protein level predicts long-term outcomes in type B acute aortic dissection. Hypertension. 2010;55:422-9.

15. Schillinger M, Domanovits H, Bayegan K, Holzenbein T, Grabenwoger M, Thoenissen J, et al. C-reactive protein and mortality in patients with acute aortic disease. Intensive Care Med. 2002;28:740-5.

16. Pencina MJ, D' Agostino RB. Overall C as a measure of discrimination in survival analysis: model specific population value and confidence interval estimation. Stat Med. 2004;23:2109-23.

17. Pencina MJ, D'Agostino RB Sr, D'Agostino RB Jr, Vasan RS. Evaluating the added predictive ability of a new marker: from area under the ROC curve to reclassification and beyond. Stat Med. 2008;27:157-72.

18. Danesh J, Wheeler JG, Hirschfield GM, Eda S, Eiriksdottir G, Rumley A, et al C-reactive protein and other circulating markers of inflammation in the prediction of coronary heart disease. N Engl J Med. 2004;350:1387-97.

19. Domanovits H, Schillinger M, Mullner M, Holzenbein T, Janata K, Bayegan K, et al. Acute phase reactants in patients with abdominal aortic aneurysm. Atherosclerosis. 2002;163:297-302.

20. Liuzzo G, Biasucci LM, Gallimore JR, Grillo RL, Rebuzzi AG, Pepys MB, et al. The prognostic value of $\mathrm{C}$-reactive protein and serum amyloid a protein in severe unstable angina. N Engl J Med. 1994;331:417-24.

21. Ridker PM, Buring JE, Cook NR, Rifai N. C-reactive protein, the metabolic syndrome, and risk of incident cardiovascular events: an 8-year follow-up of 14,719 initially healthy American women. Circulation. 2003;107:391-7.

22. Kitai T, Kaji S, Yamamuro A, Tani T, Kinoshita M, Ehara N, et al. Detection of intimal defect by 64-row multidetector computed tomography in patients with acute aortic intramural hematoma. Circulation. 2011;124:S174-8. 